\title{
Theory of mind and mentalizing ability in antisocial personality disorders with and without psychopathy
}

\author{
M. DOLAN* AND R. FULLAM \\ University of Manchester, UK; Bolton Salford and Trafford Mental Health NHS Trust, UK; the Edenfield \\ Centre, Bolton Salford and Trafford Mental Health NHS Trust, UK
}

\begin{abstract}
Background. The literature on Theory of Mind (ToM) in antisocial samples is limited despite evidence that the neural substrates of theory of mind task involve the same circuits implicated in the pathogenesis of antisocial behaviour.
\end{abstract}

Method. Eighty-nine male DSM-IV Antisocial Personality Disordered subjects (ASPDs) and 20 controls (matched for age and IQ) completed a battery of ToM tasks. The ASPD group was categorized into psychopathic and non-psychopathic groups based on a cut-off score of 18 on the Psychopathy Checklist: Screening Version.

Results. There were no significant group (control $v$. psychopath $v$. non-psychopathic ASPD) differences on basic tests of ToM but both psychopathic and non-psychopathic ASPDs performed worse on subtle tests of mentalizing ability (faux pas tasks). ASPDs can detect and understand faux pas, but show an indifference to the impact of faux pas. On the face/eye task non-psychopathic ASPDs showed impairments in the recognition of basic emotions compared with controls and psychopathic ASPDs. For complex emotions, no significant group differences were detected largely due to task difficulty.

Conclusions. The deficits in mentalizing ability in ASPD are subtle. For the majority of criminals with ASPD and psychopathy ToM abilities are relatively intact and may have an adaptive function in maintaining a criminal lifestyle. Our findings suggest the key deficits appear to relate more to their lack of concern about the impact on potential victims than the inability to take a victim perspective. The findings tentatively also suggest that ASPDs with neurotic features may be more impaired in mentalizing ability than their low anxious psychopathic counterparts.

\section{INTRODUCTION}

The antisocial personality disorders [DSM-IV antisocial personality disorder (ASPD) and psychopathy] are a group of overlapping disorders of personality that are associated with significant intra- and inter-personal dysfunction.

There is increasing recognition in the literature that ASPD and psychopathy are complex constructs and that both disorders comprise a

\footnotetext{
* Address for correspondence: Dr Mairead Dolan, Edenfield Centre, Bolton Salford and Trafford Mental Health NHS Trust, Bury New Road, Prestwich, Manchester M25 3BL, UK.

(Email: mdolan@edenfield.bstmht.nhs.uk)
}

constellation of symptoms and behaviours. While the DSM-IV category of ASPD does not provide a description of specific emotional difficulties, Hare's (1991) construct of psychopathy emphasizes interpersonal features such as callous unemotional style and lack of empathy particularly in its factor 1 item content.

There are a number of theories relating to the development of antisocial behaviour, the most prominent of which are the punishment/low fear theories (Lykken, 1995); the Response Modulation deficit hypothesis (Patterson \& Newman, 1993; Newman, 1998) and more recently the 'Violence Inhibition Mechanism' 
(VIM) deficit proposed by Blair (1995). In the latter model psychopathic behaviours and low empathy are perceived to be the result of a failure of basic emotions (e.g. fear) to result in autonomic arousal and the inhibition of ongoing behaviour.

To date, studies of antisocial behaviour have concentrated largely on the role of the ventromedial cortex (Eslinger \& Damasio, 1985; Damasio et al. 1994; Blair \& Cipolotti, 2000; Dolan \& Park, 2002). Case reports of prefrontal brain injury indicate clear associations with the development of antisocial behaviour and a pseudo-psychopathic presentation (Benson \& Blumer, 1975; Damasio, 1994). The dorsolateral prefrontal cortex mediates executive functions such as the ability to plan, monitor and inhibit pre-programmed behaviour (Smith \& Jonides, 1999). The ventromedial prefrontal cortex is implicated in inhibitory control but is particularly associated with the ability to learn to inhibit a behaviour which is no longer positively rewarding, i.e. to reverse a behavioural pattern that has changed from positively to negatively rewarded (Damasio, 1994; Dias et al. 1996; Rolls, 1997). Dysfunction in these brain regions could account for the variety of interpersonal and behavioural problems seen in ASPD and psychopathy and there is now reasonable empirical evidence based on neuropsychological testing that ASPDs exhibit a variety of executive deficits (Gorenstein, 1982; Dinn \& Harris, 2000; Dolan \& Park, 2002) compared with healthy controls.

Studies in animal and humans also demonstrate a potential role for the amygdala in emotional reactions and the modulation of the acquisition of fear motivated learning (Gallagher \& Holland, 1994). Blair \& Frith (2000) suggest that the amygdala may be a core component of the neural circuit that mediates the VIM and have proposed that early amygdala dysfunction may result in the development of core psychopathic (affective-interpersonal) traits. Amygdala lesions in humans reduce the ability to acquire conditioned autonomic responses (Bechara et al. 1995) and impair the capacity to recall emotional material (Cahill et al. 1995). Functional imaging studies confirm the notion that the amygdala is activated in affectively loaded visual stimuli particularly fearful faces (Breiter et al. 1996;
Morris et al. 1996; Phillips et al. 1997; Blair et al. 1999).

It has been proposed that patients with antisocial personality disorders particularly those with psychopathic traits have deficits in empathy (Blair, 1995). Empathy is an essential component of effective social communication and prosocial behaviour (Eisenberg \& Strayer, 1987; Hoffman, 1987). It involves role or perspective taking (Perry et al. 2001) and the ability to attribute thoughts and feelings to self and others [i.e. 'Theory of Mind' (ToM; Premack \& Woodruff, 1978) or 'mentalizing' (Frith et al. 1991)]. Recent developments in moral psychology emphasize the role of emotion and empathy in moral development and behaviour (Gilligan, 1993).

Available studies examining ToM ability in antisocial subjects have produced inconsistent findings with some (Gough, 1948; Chandler, 1973; Widom, 1976; Lee \& Prentice, 1988; Hughes et al. 1998) but not all (Blair et al. 1996; Richell et al. 2003) reporting impairments. Early work by Blair et al. $(1995,1996)$ suggested subjects characterized as prototypical psychopaths using Hare's criteria have impairments in moral/conventional distinctions (Blair et al. 1995), but not on simple ToM stories compared with non-psychopathic criminals (Blair et al. 1996). Recently, Richell et al. (2003) have also failed to show a psychopathy-specific deficit on an advanced ToM task devised by Baron-Cohen et al. $(1997,2001)$.

As the latter studies do not include a healthy control comparison group it is premature to conclude that antisocial populations do not have deficits in ToM.

We investigated empathy and ToM in ASPDs, with and without psychopathy, and healthy controls (screened for Axis I pathology and substance misuse). We hypothesized that ASPDs will not exhibit gross deficits in ToM tasks assessing basic mentalizing ability, but that subtle deficits would be apparent on more challenging ToM tasks tapping the emotions and feelings of others. We also hypothesized that 'psychopathic' ASPDs would be less impaired on ToM tasks than non-psychopathic ASPDs in the light of Blair's (1996) report that psychopathy assessed using Hare's (1991) criteria was not associated with deficits in mentalizing ability. 
Table 1. General characteristics of sample, mean (S.D.)

\begin{tabular}{|c|c|c|c|c|c|}
\hline & Controls & Non-psychopaths & Psychopaths & & \\
\hline General characteristics & $(n=20)$ & $(n=59)$ & $(n=30)$ & $F$ & $p$ value \\
\hline Age & $31 \cdot 65(7 \cdot 7)$ & $33 \cdot 03(5 \cdot 7)$ & $30 \cdot 97(5 \cdot 44)$ & $1 \cdot 25$ & $0 \cdot 29$ \\
\hline NART & $106 \cdot 9(11 \cdot 8)$ & $101 \cdot 55(13 \cdot 36)$ & $105 \cdot 4(13.8)$ & $1 \cdot 61$ & $0 \cdot 20$ \\
\hline Years of education & $12 \cdot 20(0 \cdot 61)$ & $12 \cdot 05(0 \cdot 79)$ & $11 \cdot 96(0 \cdot 18)$ & $0 \cdot 76$ & $0 \cdot 46$ \\
\hline Interpersonal Reactivity Index & $(n=17)$ & $(n=57)$ & $(n=28)$ & & \\
\hline Perspective taking & $16 \cdot 70(3 \cdot 29)$ & $16.87(5.08)$ & $16 \cdot 21(6 \cdot 43)$ & 0.65 & $0 \cdot 86$ \\
\hline Empathic concerns & $17 \cdot 88(2 \cdot 89)$ & $17.98(4.92)$ & $17 \cdot 64(6.06)$ & $0 \cdot 04$ & $0 \cdot 95$ \\
\hline Fantasy & $13 \cdot 35(5 \cdot 07)$ & $13 \cdot 33(5 \cdot 07)$ & $14 \cdot 25(6 \cdot 65)$ & $0 \cdot 27$ & $0 \cdot 76$ \\
\hline Personal distress & $9 \cdot 35(5 \cdot 23)$ & $11 \cdot 56(5 \cdot 12)$ & $10 \cdot 82(4 \cdot 60)$ & $1 \cdot 34$ & $0 \cdot 26$ \\
\hline Psychopathy checklist: screening version & $(n=20)$ & $(n=59)$ & $(n=30)$ & $T$ & \\
\hline Factor I & - & $6 \cdot 38(2 \cdot 21)$ & $9 \cdot 40(1 \cdot 52)$ & $-6 \cdot 68$ & $<0.001$ \\
\hline Factor II & - & $7.73(1.88)$ & $9 \cdot 64(1 \cdot 46)$ & $-5 \cdot 32$ & $<0.001$ \\
\hline Total & - & $14 \cdot 16(2 \cdot 37)$ & $19 \cdot 23(1 \cdot 06)$ & $-11 \cdot 1$ & $<0 \cdot 001$ \\
\hline
\end{tabular}

$\mathrm{df}=2,99$.

NART, National Adult Reading Test.

\section{METHOD}

\section{Subjects}

Eighty-nine male, right-handed subjects, aged between 18 and 55 years, meeting DSM-IV criteria for ASPD [Structured Clinical Interview for Diagnosis for Axis II disorder (SCID-II; First et al. 1997)] were recruited from prison (HMP Garth, $n=79$ ) and a maximum-security hospital (Ashworth Hospital). Subjects were detained for a minimum of 12 months and had a mean age of 36.73 years (S.D. $=9.85$ years) and, the mean number of years spent in education was 11.97 (s.D. $=0.82$ ). Full-scale National Adult Reading Test (NART; Nelson, 1982) IQ scores were within the normal range (see Table 1). All subjects were incarcerated for violent offences, but had extensive criminal histories for acquisitive offences. A single trained rater made psychopathy ratings based on file review and semi-structured interview using the Psychopathy Checklist: Screening Version (PCL-SV; Hart et al. 1995).

Twenty male healthy volunteers were recruited from ancillary staff working in secure psychiatric hospital settings and prisons. Controls were screened for Axis II pathology (SCID-II; First et al. 1997). The mean age of controls was 33.60 years (S.D. $=4.86$ years), and mean years of education $12 \cdot 0($ S.D. $=0 \cdot 56)$. There were no significant differences between controls and antisocial subjects in terms of age, IQ or years in education (see Table 1).
All Subjects (healthy controls and antisocial subjects) were screened for current Axis I disorder including affective disorder and schizophrenia (SCID-I; First et al. 1996), learning disability, significant head injury and drug or alcohol abuse. No subjects were on psychotropic medication, which might have affected neuropsychological test performance.

\section{Procedure}

The North West Region's Multi-Centre Research Ethics Committee approved the study. Written informed consent was obtained from all subjects. No subjects received financial remuneration for participation.

Subjects completed the NART as a proxy measure of intellectual function. Participants were tested individually in an interview room attached to their ward/wing. Testing typically took place within one session and all tasks were completed as part of a larger battery of tests.

\section{Psychopathy assessment}

Psychopathy was assessed using The Psychopathy Checklist: Screening Version (PCL-SV; Hart et al. 1995) and was based on file review and interview with the ASPD incarcerated group.

Factor 1 of the PCL-SV reflects affective and interpersonal traits and factor 2 reflects behavioural or social deviance components of psychopathy. Subjects scoring greater than 18 on the PCL-SV were rated as psychopathic. 
Subjects scoring less than 17 were considered non-psychopathic.

\section{Psychometric measures of empathy/perspective taking}

The Interpersonal Reactivity Index (IRI; Davis, 1980 ) is a 28-item, self-report measure of empathy with 4 subscales containing 7 items each rated on a Likert-type scale The perspective taking subscale is a measure of the ability to appreciate another's point of view. The Personal Distress scale measures the extent to which an individual can share negative emotions with others. The Fantasy Scale measures the ability to identify with imaginary characters. The Empathic Concern scale measures the ability to sympathize with less fortunate others.

Davis (1980) reports internal consistencies ranging from 0.68 to 0.79 for the subscales, and test-retest reliabilities ranging from 0.61 to $0 \cdot 81$ over interval of between 60 and 75 days. The construct validity of the scales has been supported through correlations with other empathy measures (Davis, 1983).

\section{ToM tasks}

ToM was assessed using tasks developed by Stone et al. (1998). Each task consisted of a short story followed by a number of questions relating to that story. Stories were printed onto A4-sized paper using font 16. Each story was read out and then placed in front of the participant, removing any memory load from the tasks. Participants were advised to listen to the story and to refer to the printed version if necessary. They were told that the subsequent questions would relate to various aspects of the story including the characters beliefs and/or feelings.

As ToM follows a stereotyped sequence of development, which may break down at any stage, the tasks ranged from simple false-belief problems to faux-pas tasks, which index more subtle ToM deficits.

\section{First-order false belief tasks}

These tasks require the participant to infer that someone holds a mistaken belief, which differs from their own true belief. Stories usually involved the movement of an object from the location at which the person left it to another location whilst the person is out of the room. The participant was asked questions relating to the beliefs of the person on his or her return. These included a 'belief', a 'reality' and a 'memory' question.

The belief question requires an understanding of another's mental state whilst the reality and memory questions ensure that the participant has comprehended and remembered the story correctly.

\section{Second-order false belief tasks}

These tasks test a person's ability to understand what the first person thinks about what a second person thinks. In these stories the first person leaves an object somewhere and then leaves the room. While the first person is out of the room he/she looks back and sees a second person moving the object without the second person realizing that the first person has seen this. The participant is then required to represent not only each person's belief about the location of the object, but also the second person's mistaken belief about the first person's belief state. Four questions were asked including a belief, reality, memory and a physical inference question. The latter was included to address a possible confound in the first-order false belief tasks, whereby the belief question is both the only question to ask about mental states and the only question that requires an inference rather than just understanding and memory of the story.

\section{Faux pas tasks}

A faux pas occurs when someone says something that they should not have said without realizing that they should not have said it. An understanding of faux pas requires a person to represent the mental state of both the speaker and hearer of the faux pas, i.e. it requires an understanding that the speaker does not realize they should not have said it, and that the person on the receiving end of the faux pas will feel hurt or insulted. Subjects were presented with a story containing a faux pas. They were then asked a series of questions that address detection and understanding of the faux pas, the mental state of the listener and the mental state of the speaker. An additional control question assessed general ability to follow the story and an 
empathy question addressed how the people in the story might have felt.

\section{Facial emotional expression task}

Participants' abilities to attribute both basic emotions and complex mental states to an actor based on her facial expression were assessed using a set of standardized photographs produced by Baron-Cohen et al. (1997). The seven basic emotions of: happy, sad, angry, afraid, surprise, disgust and distress were used, with happy, surprise and angry each photographed in two poses to create a set of 10 images. For the complex mental states: scheming, guilt, thoughtful, admiring, quizzical, flirting, bored, interested and arrogant were used with interested photographed in two poses, again to create a set of 10 pictures. A second set of the images was also used in which all but the eye area of each photograph was covered. All 40 A4-sized, black-and-white photographs were presented to each participant in a folder, one photograph per page in the order: basic emotions - full face, complex mental states - full face, basic emotions - eyes only, complex mental states-eyes only. At the bottom of each photograph were printed two emotion/mental state terms: the target word that described the mental state that the actor was posing and a 'foil'. In each case the foil had the same valence (positive or negative) as the target word and also belonged to the same super-ordinate semantic category as the target word, i.e. if the target was a basic emotion then so was the foil.

Participants were instructed to work through the folder and for each stimulus to decide, as quickly as possible, which of the two words under each photograph best described what the actor was thinking or feeling. The task was a forced-choice so that no answer other than one of the two terms underneath the photograph was accepted.

\section{Data analysis}

The data were analysed using SPSS version 11.1 (Chicago, IL). Group assignment in the patient/ prisoner cohort of ASPDs was based on a PCL-SV cut-off score of $>18$ (psychopaths) and $<17$ (non-psychopaths). A cut-off score of 18 is comparable to a $>30$ cut-off for prototypical psychopathy using the PCL-R. Group (control, non-psychopaths, psychopaths) comparisons on all tasks were made using parametric and non-parametric analyses of variance (KruskalWallis test) where appropriate. Post hoc testing using least significant difference method was used for normally distributed data. Not all subjects completed all tasks and the differing numbers participating in each task are shown in the subsequent tables.

\section{RESULTS}

\section{Characteristics of the sample}

The PCL-SV total and subscale scores and the mean scores on the IRI are shown in Table 1. Among the ASPD sample, as a whole, the mean PCL-SV score was $15 \cdot 87$ (s.D. $=3 \cdot 1$ ) with factor 1 scores of $7 \cdot 40$ (s.D. $=2 \cdot 45)$ and factor 2 scores of 8.44 (2.02). As expected based on the cut-off scores for categorization psychopaths had significantly higher total and PCL factor 1 (interpersonal/affective) and 2 (social deviance) scores than non-psychopaths.

There were no significant differences between controls, psychopaths and non-psychopaths in the total or subscale scores on the selfreport Interpersonal Reactivity Index (IRI; see Table 1).

\section{ToM tasks}

There were no significant group (controls, psychopaths, non-psychopaths) differences in the number of subjects passing the ToM first and second-order false beliefs tasks. That is there were no notable deficits in the belief, reality and memory components of each task, indicating that all subjects followed the task and showed similar mentalizing abilities at least in basic ToM tasks (see Table 2).

\section{Faux pas tasks}

On the faux pas task, there were also no significant group differences in the number of subjects who correctly identified all faux pas questions (Kruskal-Wallis $\chi^{2}=2 \cdot 47, \mathrm{df}=2, p=0 \cdot 29$ ) or the number correctly answering who had committed the faux pas $\left(\chi^{2}=0 \cdot 19, \mathrm{df}=2, p=0 \cdot 90\right)$. Across all 10 stories, there were no significant differences in mean scores for detection $[F(2,102)=0 \cdot 50, p=0 \cdot 60]$ or understanding who committed the faux pas $[F(2,102)=0.74$, $p=0 \cdot 47]$. (See Table 3.) 
Table 2. Theory of mind task; number of subjects passing each component of the task, $n(\%)$

\begin{tabular}{llcl}
\hline \hline & $\begin{array}{c}\text { Controls } \\
(n=20)\end{array}$ & $\begin{array}{c}\text { Non-psychopaths } \\
(n=59)\end{array}$ & $\begin{array}{c}\text { Psychopaths } \\
(n=30)\end{array}$ \\
\hline $\begin{array}{l}\text { First order } \\
\text { Belief }\end{array}$ & $19(95)$ & $55(93)$ & $29(96 \cdot 6)$ \\
Reality & $19(95)$ & $54(91 \cdot 5)$ & $27(81)$ \\
$\quad$ Memory & $19(95)$ & $56(95)$ & $28(93 \cdot 3)$ \\
Second order & & & \\
$\quad$ Belief & $19(95)$ & $53(89 \cdot 8)$ & $29(96 \cdot 6)$ \\
Reality & $20(100)$ & $54(91 \cdot 5)$ & $30(100)$ \\
Memory & $20(100)$ & $57(96 \cdot 6)$ & $29(96 \cdot 6)$ \\
Interference & $20(100)$ & $58(98 \cdot 3)$ & $30(100)$ \\
\hline \hline
\end{tabular}

Table 3. Faux pas task, mean (s.D.) scores

\begin{tabular}{|c|c|c|c|c|c|}
\hline & $\begin{array}{l}\text { Controls } \\
(n=20)\end{array}$ & $\underset{(n=57)}{\mathrm{NP}}$ & $\begin{array}{c}\mathrm{P} \\
(n=28)\end{array}$ & $F$ & $p$ value \\
\hline Detected & $8 \cdot 35(1.63)$ & $8.29(1 \cdot 80)$ & $8 \cdot 72(1.92)$ & 0.50 & 0.61 \\
\hline Understood & $8 \cdot 30(1.62)$ & $7 \cdot 76(2 \cdot 14)$ & $8 \cdot 24(2 \cdot 16)$ & 0.74 & $0 \cdot 48$ \\
\hline \multicolumn{6}{|l|}{ Mental State } \\
\hline I & $8 \cdot 25(1 \cdot 65)$ & $6 \cdot 21(2 \cdot 80)$ & $6 \cdot 36(2 \cdot 56)$ & $4 \cdot 85$ & $0 \cdot 01$ \\
\hline II & $8.25(1.74)$ & $4 \cdot 69(3.0)$ & $4.92(2.98)$ & $12 \cdot 48$ & $0 \cdot 000$ \\
\hline \multicolumn{6}{|l|}{ ToM } \\
\hline Control & $11 \cdot 0(0 \cdot 0)$ & $10 \cdot 71(0 \cdot 70)$ & $10 \cdot 7(0 \cdot 70)$ & 1.69 & $0 \cdot 18$ \\
\hline Empathy & $9 \cdot 0(1 \cdot 12)$ & $7 \cdot 21(1 \cdot 81)$ & $7 \cdot 80(1 \cdot 82)$ & $8 \cdot 06$ & 0.001 \\
\hline
\end{tabular}

$\mathrm{df}=2,202 ; \mathrm{P}$, psychopaths; NP, non-psychopaths; ToM, Theory of Mind.

Mental State I = Speaker; Mental State II = Listener.

There were, however, significant group differences on the assessment of the mental state of the listener $[F(2,102)=4 \cdot 85, p=0.01]$ and the mental state of the speaker $[F(2,102)=12 \cdot 48$, $p=0.001]$. Post hoc testing indicated that both psychopaths and non-psychopathic criminals were impaired on this aspect of the task compared with controls.

There were no significant group differences in the control question $[F(2,102)=1 \cdot 69, p=0 \cdot 1]$, indicating that subjects did not differ in their overall understanding of the story. For the empathic understanding question, however, there were significant group differences $[F(2,102)=$ $8 \cdot 06, p=0 \cdot 001]$. Post hoc testing indicated that both non-psychopathic and psychopathic criminals were impaired on this component of the task compared with controls.

\section{Baron-Cohen faces task}

Basic mental states

We compared performance on the whole face and eyes only task in the overall sample and
Table 4. Face/eye emotional cognition task

\begin{tabular}{|c|c|c|c|}
\hline & $\begin{array}{l}\text { Controls } \\
(n=20)\end{array}$ & $\begin{array}{l}\text { Non-psychopaths } \\
\quad(n=56)\end{array}$ & $\begin{array}{c}\text { Psychopaths } \\
\quad(n=28)\end{array}$ \\
\hline \multicolumn{4}{|l|}{ Basic faces } \\
\hline Median (quartiles) & $10(9-10)$ & $9(7 \cdot 5-9)$ & $9(8-10)$ \\
\hline Mean (s.D.) & $9 \cdot 2(1 \cdot 23)$ & $8 \cdot 41(1 \cdot 36)$ & $9(1 \cdot 08)$ \\
\hline \multicolumn{4}{|l|}{ Basic eyes } \\
\hline Median (quartiles)* & $9(8-9 \cdot 75)$ & $7 \cdot 5(6-9)$ & $7 \cdot 5(6-9)$ \\
\hline Mean (S.D.) & $8 \cdot 6(1.27)$ & $7 \cdot 84(1 \cdot 37)$ & $7 \cdot 71(1 \cdot 53)$ \\
\hline \multicolumn{4}{|l|}{ Complex faces } \\
\hline Median (quartiles) & $9(8-10)$ & $8(8-9)$ & $9(8-9)$ \\
\hline Mean (S.D.) & $8.9(1.07)$ & $8 \cdot 23(1 \cdot 19)$ & $8 \cdot 48(1 \cdot 15)$ \\
\hline \multicolumn{4}{|l|}{ Complex eyes } \\
\hline Median (quartiles) $\dagger$ & $9(8-9)$ & $8(7-9)$ & $8(7-9)$ \\
\hline Mean (S.D.) & $8 \cdot 41(1 \cdot 39)$ & $8 \cdot 0(1 \cdot 54)$ & $8 \cdot 17(1 \cdot 13)$ \\
\hline
\end{tabular}

* Basic eyes, Wilcoxon: controls $z=-1 \cdot 70, p<0 \cdot 08$; non-psychopaths $z=-0 \cdot 81, p=0 \cdot 41$; psychopaths $z=-1 \cdot 21, p=0 \cdot 23$.

$\dagger$ Complex eyes, Wilcoxon: controls $z=-1 \cdot 70, p<0 \cdot 0$; nonpsychopaths $z=-0 \cdot 81, p=0 \cdot 41$; psychopaths $z=-1 \cdot 21, p=0 \cdot 23$.

across groups. Data was based on the number of subjects choosing the correct mental state term for each stimulus. Overall, subjects were able to discriminate correct mental states more accurately based on faces rather than eyes (Wilcoxon $z=-4 \cdot 7, p<0 \cdot 001)$. Differences were significant for all groups. See Table 4 for median and percentile scores on this task.

Using the Kruskal-Wallis test, there were significant group differences for basic faces $\left(\chi^{2}=8 \cdot 40, \mathrm{df}=2, p<0 \cdot 01\right)$ and basic eyes task $\left(\chi^{2}=6 \cdot 14, \quad \mathrm{df}=2, \quad p<0 \cdot 05\right)$. Post hoc testing using the Mann-Whitney test indicated that there were significant differences between controls and non-psychopaths on basic faces $(z=-2 \cdot 57, p<0 \cdot 01)$ and basic eyes $(p<0.05)$. Non-psychopaths were also significantly worse than psychopaths on basic faces $(z=-1.96$, $p=0 \cdot 05)$.

\section{Complex mental states}

In the overall sample, Wilcoxon testing indicated that the whole face was better than the eyes in the recognition of complex mental states $(z=-1.92, p=0.05)$. Using the Kruskal-Wallis test, there was a trend towards significant group differences for complex faces $\left(\chi^{2}=5 \cdot 31, \mathrm{df}=2\right.$, $p=0.07)$, but no significant differences using the complex eyes task $\left(\chi^{2}=1 \cdot 24, \mathrm{df}=2, p=0 \cdot 54\right)$. Post hoc testing indicated that the significant differences were solely attributable to differences between controls and non-psychopaths for complex faces $(z=-2 \cdot 26, p<0 \cdot 05)$. 
Repeated measure analysis of variance on faces with complexity as a factor (basic $v$. complex) revealed a significant effect of group $[F(2,102)=4 \cdot 7, p=0 \cdot 01]$, a significant effect of complexity $[F(1,102)=4 \cdot 36, p=0 \cdot 04]$, but no significant complexity $\times$ group effect $[F(2,102)$ $=0.39, p=0.69]$. Post hoc testing confirmed the difference was between controls and nonpsychopaths.

A similar analysis using the eyes task revealed a non-significant effect of group $[F(2,102)=$ $1.83, \quad p=0 \cdot 16]$, complexity $[F(1,102)=0 \cdot 58$, $p=0 \cdot 44]$ and group $\times$ complexity interaction $[F(2,102)=1 \cdot 02, p=0 \cdot 36]$.

More than $50 \%$ of all subjects within each group correctly recognized all emotions except for the SCHEMING $v$. Arrogant in eyes. The same emotion was recognized equally well, however in the faces component of the task.

Non-psychopathic ASPDs compared with controls tended to have significant problems recognising DISTRESS $v$. Sadness $\left(\chi^{2}=4 \cdot 45\right.$, $\mathrm{df}=1, p<0.05)$ and ARROGANT $v$. Guilt in faces $\left(\chi^{2}=5 \cdot 60, \mathrm{df}=1, p<0 \cdot 01\right)$. Psychopathic and non-psychopathic ASPDs were both impaired on the recognition of THOUGHTFUL $v$. Arrogant in eyes compared with controls [psychopaths $v$. controls $\left(\chi^{2}=4.89, \mathrm{df}=1\right.$, $p<0.05)$; non-psychopaths $v$. controls $\left(\chi^{2}=\right.$ $6 \cdot 12, \mathrm{df}=1, p<0 \cdot 01)]$.

\section{DISCUSSION}

We compared an incarcerated sample of criminal ASPD subjects with healthy controls on a battery of ToM tasks previously used in other disorders characterized by deficits in social and emotional information processing, e.g. autistic spectrum disorders (Baron-Cohen et al. 1997) and in some studies in psychopathic populations (Blair et al. 1996). We selected a violent criminal population as we anticipated higher prevalence rates of ASPD and psychopathy than would be found in community studies (Hare, 1998). Furthermore, we recruited from an incarcerated population that was subject to random drug screens in order to minimize the likelihood of current substance misuse problems.

We screened the ASPDs and controls to exclude Axis I pathology and medication use to ensure that our findings could not be attributed to co-morbid psychopathology or substance misuse. As we were particularly interested in differences between psychopathic and nonpsychopathic criminals with ASPD, subjects were rated using the screening version of the Psychopathy Checklist as this measure is increasingly recognize as useful in discriminating those with callous-unemotional traits or core psychopathic traits from those who do not have these characteristics. We used the US cut-off of $>18$ to assign a diagnosis of psychopathy. We did not select a score $<12$ as representative of non-psychopathic status due to the low numbers scoring in this range. However, we repeated the analysis using the latter cut-off for non-psychopathic status and found essentially similar findings. The PCL-SV was not used in healthy controls as it relies heavily on file reports of criminal/antisocial behaviour, which are not applicable to staff controls as they had criminal records checks and were screened for Axis II pathology.

\section{Psychometric measures of empathy/perspective taking}

We were unable to detect any significant group differences on any of the subscales of the IRI including perspective taking and empathic concern. The latter finding may reflect deception in the antisocial group but also, possibly, the impact on staff controls of working with offenders. Indeed our controls had lower than expected scores for empathy compared to those cited by Davis (1983) for men in the general population.

Previous studies comparing control and pathological samples on self-report empathy measures have produced inconsistent findings, with some (Hogan, 1969; Ellis, 1982) but not all (Kendall \& Deardorff, 1977; Kaplan \& Arbuthnot, 1985; Lee \& Prentice, 1988) reporting differences between offender and healthy control groups. Our findings also fit with reports that role-taking impairments are less obvious in adult criminals (Hickey, 1972; Widom, 1978) than delinquents (Chandler, 1973; Lee \& Prentice, 1988). This may well be developmental, but it also suggests that adult criminals may require role-taking ability in order to manipulate others. Overall, our findings and the general literature in this field casts doubt on the validity 
of self-report empathy measures in criminal populations (Eisenberg \& Strayer, 1987).

\section{ToM tasks}

Similar to Blair et al. (1996) we did not find gross impairments in first and second order false beliefs in the psychopathic and non-psychopathic adult criminals. Previous studies in low functioning autistic groups have demonstrated impairments in first and second order false beliefs (Baron-Cohen et al. 1985; Perner et al. 1987). By contrast, subjects with Asperger's Syndrome can pass first and second order tasks (see Baron-Cohen et al. 1997). Differences in IQ may account for these discrepant findings.

It is also possible that there are ceiling effects in ToM tasks in criminal samples of at least average intellectual ability. Deficits may be seen in less able samples with antisocial behaviours or in delinquents.

\section{Faux pas task}

In this study we did not detect any significant differences between the groups in their ability to detect and understand a faux pas. This suggests that the ASPD groups do not have gross impairments in the cognitive ability to represent the mental state of the speaker and listener. However, psychopathic and non-psychopathic ASPDs were both impaired in their responses to questions relating to how the speaker and listener might have felt once the faux pas had been made. This finding suggests difficulty in truly empathizing with the characters in the stories or an indifference to the impact of the faux pas on the speaker or the listener. In the majority of cases ASPDs justified their responses with concrete statements, e.g. 'the speaker was simply saying what they thought as the curtains were disgusting'.

\section{Basic and complex mental states - facial/eye expression}

As in previous studies (e.g. Baron-Cohen et al. 1997) we found that all our groups were able to detect a range of mental states both basic and complex from whole facial expressions and that faces provide significantly more information than eyes for basic emotions. This fits with Baron-Cohen et al.'s (1997) concept of a
'Language of the eyes'. For complex mental states seeing the eyes or the face did not reveal significantly different scores among the groups. Baron-Cohen et al. (1997) have shown that high functioning patients with autism and Asperger's syndrome have impairments in complex mental states particularly in the eyes alone task compared with healthy controls. In this study, we found that our healthy control sample performed similarly to Baron-Cohen et al.'s 1997 normative sample. Over half the sample in all groups had difficulty recognizing SCHEMING in eyes but not in faces. This suggests a task difficulty effect and indicates some complex emotions require more information for accurate identification. Since this study this task has now been modified to address some of these difficulties (Baron-Cohen et al. 2001).

We found non-psychopathic ASPDs performed worse than controls and psychopathic ASPDs on some, but not all, basic emotions. This was most notable for DISTRESS $v$. Sadness and ARROGANT $v$. Guilt in faces and, when GUILT was the target emotion in eyes. Our findings largely support Blair et al.'s (1995) report that psychopathic offenders have specific impairments in their emotional attributions relating to guilt presented in story format. As the eye task is more difficult than the face task, it is possible that task difficulty is an important confound for complex emotions such as guilt. Recently, Richell et al. (2003) reported that psychopathic and non-psychopathic criminals did not differ significantly on a revised version of the Eye task. However, they did not report on individual emotions, so comparisons are difficult. One other possible explanation for the discrepant findings between studies using this task is that subjects differ in the degree of their neuroticism and their early socialization. In this sample non-psychopathic ASPDs had the most difficulty in interpreting emotional expressions. They were also those who would be characterized as 'secondary psychopaths' (neurotic psychopaths) based on Blackburn's (1998) typology and who had come from adverse family backgrounds. Previous studies have shown that aggressive children from deprived family backgrounds respond to distress in others with aggression (Dodge, 1982). Others (e.g. Stevens et al. 2001) have shown that children with psychopathic traits have impairments in the 
recognition of sad and fearful emotions rather than anger and happiness. Future studies need to consider the developmental pathways that result in adult ASPD and psychopathy and the role of anxiety and neuroticism in the misinterpretation of emotional expression and mentalizing ability.

Overall, our findings suggest that ASPDs with psychopathic traits do not have marked difficulties in reading basic or complex emotions from facial expression. In fact, they perform remarkably similar to health controls if not slightly better in some areas of complex emotional recognition.

Our work adds to the literature by clarifying that psychopathic and non-psychopathic offenders have mild impairments in higher order ToM tasks compared with controls and these largely reflect a difficultly in empathic understanding. The study also highlights the difficulty of reliance on self-report measures of empathy. Limitations of this study include the relatively small sample size of the control group and reliance on correctional staff controls. A further limitation is the possibility that there may have been a ceiling effect for the basic ToM tasks as they were originally designed for use in younger samples. The transparency of self-report empathy assessments is a further challenge in criminal samples where social desirability bias may be a factor.

Future studies need to use psychophysiological or more covert measures of emotional responsivity and empathy. As the amygdala and orbitofrontal cortex have been implicated in the neural network sub-serving empathic understanding and emotional recognition functional imaging studies are needed to clarify the nature of any reported affective empathic deficits in antisocial populations. A recent event-related fMRI study by Berthoz et al. (2002) in healthy subjects indicates that transgressions of social norms activate the prefrontal and temporal regions previously reported to play a role in representing mental states of others. Similar work is required in antisocial samples. This study concentrated on a highly selected sample. Further studies are therefore required in antisocial groups with and without co-morbid psychopathology and substance misuse to assess the impact of co-morbid disorders on mentalizing ability.

\section{ACKNOWLEDGEMENTS}

The work was supported by the ESRC (grant ref. no. R000223591). We thank the staff and participants at key institutions. We also thank Siobhan Smyth and Emma Naylor for their assistance in data collection.

\section{DECLARATION OF INTEREST}

None.

\section{REFERENCES}

Baron-Cohen, S., Leslie, A. \& Frith, U. (1985). Does the autistic child have a 'theory of mind'? Cognition 21, 37-46.

Baron-Cohen, S., Wheelwright, S., Hill, J., Raste, Y. \& Plumb, I. (2001). The 'Reading the Mind in the Eyes' test revised version: a study with normal adults, and adults with Asperger syndrome of high functioning autism. Journal of Child Psychology and Psychiatry 42, 241-251.

Baron-Cohen, S., Wheelwright, S. \& Jolliffe, T. (1997). Is there a 'language of the eyes'? Evidence from normal adults, and adults with Autism or Asperger's syndrome. Visual Cognition 4, 311-331.

Bechara, A., Tranel, D., Damasio, H., Adolphs, R., Rockland, C. \& Damasio, A. R. (1995). Double dissociation of conditioning and declarative knowledge relative to the amygdala and hippocampus in humans. Science 269, 1115-1118.

Benson, D. F. \& Blumer, D. (1975). Personality changes with frontal and temporal lobe lesions. In Psychiatric Aspects of Neurological Disease (ed. D. F. Benson and D. Blumer), pp. 151-170. Grune and Stratton: New York.

Berthoz, S., Armony, J. L., Blair, R. J. R. \& Dolan, R. J. (2002). An fMRI study of intentional and unintentional (embarrassing) violations of social norms. Brain 125, 1696-1708.

Blackburn, R. (1998). Psychopathy and personality disorder; implication of interpersonal theory. In Psychopathy: Theory, Research and Implications for Society (ed. D. J. Cooke, A. E. Forth and R. D. Hare), pp 269-303. Kluwer Academic Publishers: Dordrecht.

Blair, R. J. R. (1995). A cognitive developmental approach to morality: investigating the psychopath. Cognition 57, 1-29.

Blair, R. J. R. \& Cipolotti, L. (2000). Impaired social response reversal: a case of 'acquired sociopathy'. Brain 123, 1122-1141.

Blair, J. R. J. \& Frith, U. (2000). Neurocognitive explanations of the antisocial personality disorders. Criminal Behaviour and Mental Health 10, 566-581.

Blair, J. R. J., Morris, J. S., Frith, C. D., Perrett, D. I. \& Dolan, R. J. (1999). Dissociable neural responses to facial expressions of sadness and anger. Brain 122, 883-893.

Blair, R. J. R., Sellars, C., Strickland, I. \& Clark, F. (1995). Emotion attributions in the psychopath. Personality and Individual Differences 19, 431-437.

Blair, R. J. R., Sellars, C., Strickland, I., Clark, F., Williams, A., Smith, M. \& Jones, L. (1996). Theory of mind in the psychopath. Journal of Forensic Psychiatry 7, 15-25.

Breiter, H. C., Etcoff, N. L., Whalen, P. J., Kennedy, W. A., Rauch, S. L., Buckner, R. L., Strauss, M. M., Hyman, S. E. \& Rosen, B. R. (1996). Response and habituation of the human amygdala during visual processing of facial expression. Neuron 17, 875-887.

Cahill, L., Babinsky, R., Markowitsch, H. J. \& McGaugh, J. L. (1995). The amygdala and emotional memory. Nature 377, 295-296.

Chandler, M. J. (1973). Egocentrism and antisocial behaviour. The assessment and training of social perspective-taking skills. Developmental Psychology 9, 326-332. 
Damasio, A. R. (1994). Emotion, Reason and the Human Brain. Avon Science: New York.

Damasio, H., Grabowski, T., Frank, R., Galaburda, A. M. \& Damasio, A. R. (1994). The return of Phineas Gage: clues about the brain from the skull of a famous patient. Science 264, 1102-1105.

Davis, M. H. (1980). A multidimensional approach to individual differences in empathy. JSAS Catalogue of Selected Documents in Psychology 10, MS 2124, 85.

Davis, M. H. (1983). Effects of dispositional empathy on emotional reactions and helping; a multidimensional approach. Journal of Personality and Social Psychology 44, 1113-1126.

Dias, R., Robbins, A. C. \& Roberts, A. C. (1996). Dissociation in prefrontal cortex of affective and attentional shifts. Nature $\mathbf{3 8 0}$, 69-72.

Dinn, W. M. \& Harris, C. L. (2000). Neurocognitive function in antisocial personality disorder. Psychiatry Research 97, 173-190.

Dodge, K. A. \& Frame, C. L. (1982). Social cognitive biases and deficits in aggressive boys. Child Development 53, 620-635.

Dolan, M. \& Park, I. (2002). The neuropsychology of antisocial personality disorder. Psychological Medicine 32, 417-427.

Ellis, P. L. (1982). Empathy: a factor in antisocial behaviour. Journal of Abnormal Child Psychology 10, 123-134.

Eisenberg, N. \& Strayer, J. (eds) (1987). Empathy and its Development. Cambridge University Press: Cambridge, UK.

Eslinger, P. J. \& Damasio, A. R. (1985). Severe disturbance of higher cognition after bilateral frontal lobe ablation: patient EVR Neurology 35, 1731-1741.

First, M. B., Spitzer, R. L., Gibbon, M. \& Janet, B. W. (1997). Structured Clinical Interview for DSM-IV Personality Disorders $(S C I D-I I)$. American Psychiatric Press: Washington, DC.

First, M. B., Spitzer, R. L., Gibbon, M. \& Williams, J. B. W. (1996). Structured Clinical Interview for DSM-IV Axis I Disorders, Clinician Version (SCID-CV). American Psychiatric Press: Washington, DC.

Frith, U., Morton, J. \& Leslie, A. M. (1991). The cognitive basis of a biological disorder: autism. Trends in Neuroscience 14, 433-438.

Gallagher, M. \& Holland, P. C. (1994). The amygdala complex: multiple roles in associative learning and attention. Proceedings of the National Academy of Science USA 91, 11771-11776.

Gilligan, C. (1993). In a Different Voice (3rd edn). Harvard University Press: Cambridge, MA

Gorenstein, E. E. (1982). Frontal lobe functions in psychopaths. Journal of Abnormal Psychology 91, 368-379.

Gough, H. G. (1948). A sociological theory of psychopathy. American Journal of Sociology 53, 359-366.

Hare, R. D. (1991). The Hare Psychopathy Checklist-Revised. Multi-Health Systems: Toronto.

Hare, R. D. (1998). Psychopathy, affect and behaviour. In Psychopathy: Theory, Research and Implications for Society (ed. D. J Cooke, A. E. Forth and R. D. Hare), pp. 105-137. Kluwer Academic Publishers: Dordrecht.

Hart, S. D., Cox, D. N. \& Hare, R. D. (1995). The Hare Psychopathy Checklist : Screening Version (PCL-SV). Multihealth Systems Inc.: Toronto.

Hickey, J. E. (1972). The effects of guided moral discussion upon youthful offenders' level of moral judgement. Dissertation Abstracts International 33, 1551.

Hoffman, M. L. (1987). The contribution of empathy to justice and moral judgement. In Empathy and its Development (ed. N. Eisenberg and J. Strayer), pp. 47-80. Cambridge University Press: Cambridge, UK

Hogan, R. (1969). Development of an empathy scale. Journal of Consulting and Clinical Psychology 33, 307-316.
Hughes, C., Dunn, J. \& White, A. (1998). Trick or treat? Uneven understanding of mind and emotion and executive dysfunction in hard-to-manage preschoolers. Journal of Child Psychology and Psychiatry 39, 981-994.

Kaplan, P. J. \& Arbuthnot, J. (1985). Affective empathy and cognitive role-taking in the delinquent and non-delinquent youth. Adolescence 20, 323-333.

Kendall, P. C. \& Deardorff, P. A. (1977). Empathy and socialisation in first and repeat juvenile offenders and normals. Journal of Abnormal Child Psychology 5, 93-97.

Lee, M. \& Prentice, N. M. (1988). Interrelations of empathy, cognition and moral reasoning with dimensions of juvenile delinquency. Journal of Abnormal Child Psychology 16, 127-139.

Lykken, D. T. (1995). Fatherless rearing leads to sociopathy. Behavioural and Brain Sciences 18, 563-564.

Morris, J., Frith, C. D., Perrett, D. I., Rowland, D., Young, A. W. Calder, A. J. \& Dolan, R. J. (1996). A differential neural response in the human amygdala to fearful and happy facial expressions. Nature 383, 812-815.

Nelson, H. E. (ed.) (1982). The National Adult Reading Test (NART): Test Manual. NFER-Nelson: Windsor, Berkshire, UK.

Newman, J. P. (1998). Psychopathic behaviour: an information processing perspective, In Psychopathy: Theory, Research and Implications for Society (ed. D. J. Cooke, A. E. Forth and R. D. Hare), pp. 81-105. Kluwer Academic Publishers: Dordrecht.

Patterson, C. M. \& Newman, J. P. (1993). Reflectivity and learning from aversive events: toward a psychological mechanism for the syndromes of disinhibition. Psychological Review $\mathbf{1 0 0}$, 716-736.

Perner, J., Leekam, S. R. \& Wimmer, H. (1987). Three-year-old's difficulty with false belief: the case for a conceptual deficit. British Journal of Developmental Psychology 5, 125-137.

Perry, R. J., Rosen, H. R., Kramer, J. H., Beer, J. S., Levenson, R. L. \& Miller, B. L. (2001). Hemispheric dominance for emotions empathy and social behaviour: evidence from right and left handers with frontotemporal dementia. Neurocase 7, 145-160.

Phillips, M. L., Young, A. W., Senior, C., Brammer, M., Andrew, C., Calder, A. J., Bullmore, E. T., Perrett, D. I., Rowland, D., Williams, S. C. R. \& David, A. S. (1997). A specific neural substrate for facial expressions of disgust. Nature 389, 495-498.

Premack, D. \& Woodruff, G. (1978). Does the chimpanzee have a 'theory of mind'? Behaviour and Brain Sciences 4, 515-526.

Richell, R. A., Mitchell, D., Newman, C., Leonard, A., Baron-Cohen, S. \& Blair, R. J. R. (2003). Theory of Mind and psychopathy: can psychopathic individuals read the 'language of the eyes'? Neuropsychologia 41, 523-526.

Rolls, E. T. (1997). Consciousness in neural networks? Neural Networks 10, 1227-1240.

Smith, E. \& Jonides, J. (1999). Storage and executive processes in the frontal lobes. Science 12, 1657-1661.

Stevens, D., Charman, T. \& Blair, R. J. R. (2001). Recognition of emotion in facial expressions and vocal tones in children with psychopathic tendencies. Journal of Genetic Psychology 162, 201-211.

Stone, V. E., Baron-Cohen, S. \& Knight, R. T. (1998). Frontal lobe contributions to theory of mind. Journal of Cognitive Neuroscience 10, 640-656.

Widom, C. S. (1976). Interpersonal and personal construct systems in psychopaths. Journal of Consulting and Clinical Psychology 44 614-623

Widom, C. S. (1978). An empirical classification of female offenders. Criminal Justice and Behaviour 5, 35-52. 